\title{
Solvability and positive solution of a system of second-order boundary value problem with integral boundary conditions
}

\author{
Rochdi Jebari* and Abderrahman Boukricha
}

"Correspondence: rjebari@yahoo.fr Faculty of Sciences of Tunis, Tunis-El Manar University, Campus

Universitaire, El Manar, 2092, Tunisia

\begin{abstract}
The main purpose of this paper is to establish the existence, uniqueness and positive solution of a system of second-order boundary value problem with integral conditions. Using Banach's fixed point theorem and the Leray-Schauder nonlinear alternative, we discuss the existence and uniqueness solution of this problem, and we apply Guo-Krasnoselskii's fixed point theorem in cone to study the existence of positive solution. We also give some examples to illustrate our results.
\end{abstract}

Keywords: nonlinear system of second-order boundary value problem; integral conditions; Banach's fixed point theorem; Leray-Schauder nonlinear alternative; Guo-Krasnoselskii's fixed point theorem in cone

\section{Introduction}

The systems of second-order ordinary differential equations arise from many fields in physics, biology and chemistry; for example, in the theory of nonlinear diffusion generated by nonlinear sources, in thermal ignition of gases, and in concentration in chemical or biological problems (see [1-3] and the references therein). The main purpose of the present paper is to investigate sufficient conditions for the existence, uniqueness and positive solution of the following problem:

$$
u_{i}^{\prime \prime}(t)+f_{i}\left(t, u_{1}(t), \ldots, u_{n}(t)\right)=0, \quad 0<t<1,
$$

with integral conditions

$$
\left\{\begin{array}{l}
u_{i}(0)-k_{1, i} u_{i}^{\prime}(0)=\int_{0}^{1} g_{i}\left(s, u_{1}(s), \ldots, u_{n}(s)\right) d s \\
u_{i}(1)+k_{2, i} u_{i}^{\prime}(1)=\int_{0}^{1} h_{i}\left(s, u_{1}(s), \ldots, u_{n}(s)\right) d s
\end{array}\right.
$$

where for all $i \in\{1, \ldots, n\}, f_{i}:[0,1] \times \mathbb{R}^{n} \rightarrow \mathbb{R}, g_{i}:[0,1] \times \mathbb{R}^{n} \rightarrow \mathbb{R}$ and $h_{i}:[0,1] \times \mathbb{R}^{n} \rightarrow \mathbb{R}$ are given functions satisfying some assumptions that will be specified later. $k_{1, i}$ and $k_{2, i}$ are nonnegative constants. The integral conditions have physical significations such as total mass, moment, etc. Sometimes it is better to impose integral conditions to get a more accurate measure than a local condition (see [4]). Various types of boundary value problems involving integral condition have been studied by many authors using fixed point

(C) 2014 Jebari and Boukricha; licensee Springer. This is an Open Access article distributed under the terms of the Creative Commons Attribution License (http://creativecommons.org/licenses/by/4.0), which permits unrestricted use, distribution, and reproduction in any medium, provided the original work is properly credited. 
theorems on cones, fixed point index theory, the generalized quasilinearization method, the Leray-Schauder nonlinear alternative and the Leggett-Williams fixed point theorem [5-10]. In [5] Yang and Sun considered the boundary value problem of the following differential equations:

$$
\left\{\begin{array}{l}
-u^{\prime \prime}(t)=f(t, v(t))=0, \quad 0<t<1, \\
-v^{\prime \prime}(t)=g(t, u(t))=0, \quad 0<t<1, \\
u(0)=u(1)=0, \quad v(0)=v(1)=0
\end{array}\right.
$$

and by using the degree theory, the existence of a positive solution of (1.3) is established. In [6], Ma considered the following system involving second-order ordinary differential equations:

$$
\left\{\begin{array}{l}
u^{\prime \prime}(t)+a(t) f(u(t), v(t))=0, \quad 0<t<1, \\
v^{\prime \prime}(t)+b(t) g(u(t), v(t))=0, \quad 0<t<1, \\
u(0)=u(1)=0, \quad v(0)=v(1)=0,
\end{array}\right.
$$

where $a(\cdot)$ and $b(\cdot)$ are continuous functions on $[0,1]$. By the use of a fixed point theorem on cone, Ma established the existence of one positive solution of (1.4) in which $f$ and $g$ satisfy appropriate growth and boundedness conditions. In [7, 8] Khan and Ahmed et al. considered respectively the following second-order ordinary differentials equations:

$$
\left\{\begin{array}{l}
u^{\prime \prime}(t)=f(t, u(t)), \quad 0<t<1 \\
u(0)-k_{1} u^{\prime}(0)=\int_{0}^{1} h_{1}(u(s)) d s \\
u(1)+k_{2} u^{\prime}(1)=\int_{0}^{1} h_{2}(u(s)) d s
\end{array}\right.
$$

and

$$
\left\{\begin{array}{l}
u^{\prime \prime}(t)+\sigma u^{\prime}(t)+f(t, u(t))=0, \quad 0<t<1, \\
u(0)-k_{1} u^{\prime}(0)=\int_{0}^{1} h_{1}(u(s)) d s \\
u(1)+k_{2} u^{\prime}(1)=\int_{0}^{1} h_{2}(u(s)) d s
\end{array}\right.
$$

where $\sigma \in \mathbb{R} \backslash\{0\}$. The generalized method of quasilinearization is applied to obtain by iteration a monotone sequence converging uniformly and rapidly to a solution of (1.5) and (1.6). In [9] Benchohra studied the existence and uniqueness of a solution of the following second-order boundary value problem:

$$
\left\{\begin{array}{l}
u^{\prime \prime}(t)+f(t, u(t))=0, \quad 0<t<1 \\
u(0)=0 \\
u(1)=\int_{0}^{1} g(s) u(s) d s
\end{array}\right.
$$

where $g:[0,1] \rightarrow \mathbb{R}$ is an integrable function. Benchohra et al. used the Leray-Schauder nonlinear alternative to investigate the existence of solutions of (1.7) under the conditions $f$ is $L^{1}$-Carathéodory and $|f(t, u)| \leq p(t)|u|^{\alpha}+\bar{q}(t), \alpha \in\left[0,1\left[, p, q \in L^{1}\left([0,1], \mathbb{R}_{+}\right)\right.\right.$. In [10] Belarbi et al. used the Leggett-Williams fixed point theorem to study the multiple positive 
solutions for the nonlinear boundary value problem with integral boundary conditions:

$$
\left\{\begin{array}{l}
u^{\prime \prime}(t)+f(u(t))=0, \quad 0<t<1 \\
u(0)-k_{1} u^{\prime}(0)=\int_{0}^{1} h_{1}(u(s)) d s \\
u(1)+k_{2} u^{\prime}(1)=\int_{0}^{1} h_{2}(u(s)) d s
\end{array}\right.
$$

For more knowledge about the boundary value problems, we refer the reader to [11-28]. Our aim is to use the Banach contraction principle and the Leray-Schauder nonlinear alternative to prove the existence and uniqueness solutions of our problem. For this, we formulate the boundary value problem as the fixed point problem. However, the Schauder fixed point theorem cannot ensure the solutions to be positive. Since only positive solutions are useful for many applications, motivated by the above works, the existence of positive solution is obtained by Guo-Krasnoselskii's fixed point theorem. Our work is more general than [5-7, 9, 10]; for example, (1.7) investigated in the case $n=1, k_{1,1}=k_{2,1}=0$, $g_{1} \equiv 0, h_{1}(s, u(s))=g(s) u(s)$ and (1.3) in the case $n=2, k_{1,1}=k_{2,1}=k_{1,2}=k_{2,2}=0, g_{1} \equiv g_{2} \equiv$ $h_{1} \equiv h_{2} \equiv 0$. To the best of our knowledge, no one has studied the existence and positiveness of solutions for system (1.1)-(1.2).

This paper is organized as follows. In Section 2, we present some preliminaries that will be used to prove our results. In Section 3, we discuss the existence and uniqueness of a solution for problem (1.1)-(1.2) by using the Leray-Schauder nonlinear alternative and Banach's fixed point theorem. In Section 4, the study of the positivity of a solution is based on Guo-Krasnoselskii's fixed point theorem in cone. Finally, we shall give three examples to illustrate our main results.

\section{Preliminaries and lemmas}

The Cartesian product of $C([0,1] ; \mathbb{R})$ can be defined as $E=(C([0,1] ; \mathbb{R}))^{n}$ equipped with the norm

$$
\|u\|=\sum_{i=1}^{n}\left\|u_{i}\right\|_{\infty}
$$

where $u=\left(u_{1}, \ldots, u_{n}\right) \in E$. The space $E$ is a Banach space. We define, for all $x \in \mathbb{R}^{n}$,

$$
\|x\|_{1}=\sum_{i=1}^{n}\left|x_{i}\right|
$$

For all $f \in L^{1}([0,1])$,

$$
\|f\|_{L^{1}}=\int_{0}^{1}|f(s)| d s
$$

and for all $g \in L^{2}([0,1])$,

$$
\|g\|_{L^{2}}=\left(\int_{0}^{1}|g(s)|^{2} d s\right)^{\frac{1}{2}}
$$

We define the set $\mathbb{R}_{+}^{n}$ by $\mathbb{R}_{+}^{n}=\left\{\left(x_{1}, \ldots, x_{n}\right) \in \mathbb{R}^{n} ; x_{1} \in \mathbb{R}_{+}, \ldots, x_{n} \in \mathbb{R}_{+}\right\}$. 


\section{Definition 2.1}

1. The function $u=\left(u_{1}, \ldots, u_{n}\right)$ is called a nonnegative solution of system (1.1)-(1.2) if and only if $u$ satisfies (1.1)-(1.2) and for all $i \in\{1, \ldots, n\}, u_{i}(t) \geq 0$ for $t \in[0,1]$.

2. The function $u=\left(u_{1}, \ldots, u_{n}\right)$ is called a positive solution of system (1.1)-(1.2) if and only if $u$ satisfies (1.1)-(1.2) and for all $i \in\{1, \ldots, n\}, u_{i}(t)>0$ for $\left.t \in\right] 0,1[$.

Lemma 2.2 Let $i \in\{1, \ldots, n\}, f_{i}, g_{i}$ and $h_{i}$ are continuous functions. Then $u=\left(u_{1}, \ldots, u_{n}\right)$ is a solution of (1.1)-(1.2) if and only iffor all $i \in\{1, \ldots, n\}$,

$$
u_{i}(t)=P_{i}(t)+\int_{0}^{1} G_{i}(t, s) f_{i}\left(s, u_{1}(s), \ldots, u_{n}(s)\right) d s
$$

where

$$
\begin{aligned}
P_{i}(t)= & \frac{\left(1-t+k_{2, i}\right)}{k_{1, i}+k_{2, i}+1} \int_{0}^{1} g_{i}\left(s, u_{1}(s), \ldots, u_{n}(s)\right) d s \\
& +\frac{\left(t+k_{1, i}\right)}{k_{1, i}+k_{2, i}+1} \int_{0}^{1} h_{i}\left(s, u_{1}(s), \ldots, u_{n}(s)\right) d s
\end{aligned}
$$

is the unique solution of the problem

$$
\left\{\begin{array}{l}
u_{i}^{\prime \prime}(t)=0, \quad 0<t<1, \\
u_{i}(0)-k_{1, i} u_{i}^{\prime}(0)=\int_{0}^{1} g_{i}\left(s, u_{1}(s), \ldots, u_{n}(s)\right) d s, \\
u_{i}(1)+k_{2, i} u_{i}^{\prime}(1)=\int_{0}^{1} h_{i}\left(s, u_{1}(s), \ldots, u_{n}(s)\right) d s,
\end{array}\right.
$$

and

$$
G_{i}(t, s)=\frac{1}{k_{1, i}+k_{2, i}+1} \begin{cases}\left(k_{1, i}+t\right)\left(1-s+k_{2, i}\right) & \text { if } 0 \leq t \leq s \\ \left(k_{1, i}+s\right)\left(1-t+k_{2, i}\right) & \text { if } s \leq t \leq 1\end{cases}
$$

is the Green functions of the corresponding homogeneous problem.

For details of the proof of this lemma, we refer the reader to $[7,8,10]$. Now, let $T_{i}$ be the operator defined by

$$
\begin{aligned}
& T_{i}: E \rightarrow C([0,1] ; \mathbb{R}) \\
& u \mapsto T_{i}(u) \text {, }
\end{aligned}
$$

where for all $t \in[0,1]$,

$$
T_{i}(u)(t)=P_{i}(t)+\int_{0}^{1} G_{i}(t, s) f_{i}\left(s, u_{1}(s), \ldots, u_{n}(s)\right) d s,
$$

and we denote by $T$ the operator defined by

$$
\begin{array}{rlc}
T: E & \rightarrow & E \\
u & \mapsto & \left(T_{1}(u), \ldots, T_{n}(u)\right) .
\end{array}
$$

We can write Lemma 2.2 in the following form: $u=\left(u_{1}, \ldots, u_{n}\right)$ is a solution of (1.1)-(1.2) if and only if $u$ is a fixed point of the operator $T$. 


\section{Existence and uniqueness results}

Lemma 3.1 For all $i \in\{1, \ldots, n\},(t, s) \in[0,1] \times[0,1]$,

$$
0 \leq G_{i}(t, s) \leq G_{1}(s)
$$

where

$$
G_{1}(s)=\frac{\left(\max _{i \in\{1, \ldots, n\}} k_{1, i}+s\right)\left(1-s+\max _{i \in\{1, \ldots, n\}} k_{2, i}\right)}{\min _{i \in\{1, \ldots, n\}} k_{1, i}+\min _{i \in\{1, \ldots, n\}} k_{2, i}+1}
$$

Proof Let $i \in\{1, \ldots, n\}$. If $t \leq s$, then

$$
\left(k_{1, i}+t\right)\left(1-s+k_{2, i}\right) \leq\left(k_{1, i}+s\right)\left(1-s+k_{2, i}\right) .
$$

This implies that

$$
\frac{1}{k_{1, i}+k_{2, i}+1}\left(k_{1, i}+t\right)\left(1-s+k_{2, i}\right) \leq \frac{1}{k_{1, i}+k_{2, i}+1}\left(k_{1, i}+s\right)\left(1-s+k_{2, i}\right) .
$$

If $s \leq t$, then $-t \leq-s$ and

$$
\left(k_{1, i}+s\right)\left(1-t+k_{2, i}\right) \leq\left(k_{1, i}+s\right)\left(1-s+k_{2, i}\right) .
$$

This implies that

$$
\frac{1}{k_{1, i}+k_{2, i}+1}\left(k_{1, i}+s\right)\left(1-t+k_{2, i}\right) \leq \frac{1}{k_{1, i}+k_{2, i}+1}\left(k_{1, i}+s\right)\left(1-s+k_{2, i}\right) .
$$

We deduce that for all $i \in\{1, \ldots, n\}$, for all $s \in[0,1]$ and for all $t \in[0,1], 0 \leq G_{i}(t, s) \leq$ $\frac{1}{k_{1, i}+k_{2, i}+1}\left(k_{1, i}+s\right)\left(1-s+k_{2, i}\right)$. Since for all $i \in\{1, \ldots, n\}, \min _{i \in\{1, \ldots, n\}} k_{1, i} \leq k_{1, i} \leq \max _{i \in\{1, \ldots, n\}} k_{1, i}$ and $\min _{i \in\{1, \ldots, n\}} k_{2, i} \leq k_{2, i} \leq \max _{i \in\{1, \ldots, n\}} k_{2, i}$. We obtain for all $(t, s) \in[0,1] \times[0,1], i \in$ $\{1, \ldots, n\}, 0 \leq G_{i}(t, s) \leq G_{1}(s)$, where $G_{1}(s)$ is given by (3.2).

Now, we prove the existence and uniqueness of solutions in the Banach space $E$. The uniqueness result is based on Banach's contraction principle [29].

Theorem 3.2 Let $i, j \in\{1, \ldots, n\}$, assume that the functions $f_{i}, g_{i}$ and $h_{i}$ are continuous and there exist nonnegative functions $\theta_{i, j}, \varphi_{i, j}, \psi_{i, j} \in L^{1}\left([0,1], \mathbb{R}_{+}\right)$such that for all $x=$ $\left(x_{1}, \ldots, x_{n}\right), y=\left(y_{1}, \ldots, y_{n}\right) \in \mathbb{R}^{n}$ and $t \in[0,1]$,

1. $\left|f_{i}\left(t, x_{1}, \ldots, x_{n}\right)-f_{i}\left(t, y_{1}, \ldots, y_{n}\right)\right| \leq \sum_{j=1}^{n} \theta_{i, j}(t)\left|x_{j}-y_{j}\right| ;$

2. $\left|g_{i}\left(t, x_{1}, \ldots, x_{n}\right)-g_{i}\left(t, y_{1}, \ldots, y_{n}\right)\right| \leq \sum_{j=1}^{n} \varphi_{i, j}(t)\left|x_{j}-y_{j}\right|$;

3. $\left|h_{i}\left(t, x_{1}, \ldots, x_{n}\right)-h_{i}\left(t, y_{1}, \ldots, y_{n}\right)\right| \leq \sum_{j=1}^{n} \psi_{i, j}(t)\left|x_{j}-y_{j}\right|$;

4. $C \sum_{i=1}^{n} \sum_{j=1}^{n}\left\|\psi_{i, j}\right\|_{L^{1}}+K \sum_{i=1}^{n} \sum_{j=1}^{n}\left\|\varphi_{i, j}\right\|_{L^{1}}+\sum_{i=1}^{n} \sum_{j=1}^{n}\left\|G_{1}\right\|_{L^{2}}\left\|\theta_{i, j}\right\|_{L^{2}}<1$,

where

$$
C=\frac{\left(2+\max _{i \in\{1, \ldots, n\}} k_{2, i}\right)}{\min _{i \in\{1, \ldots, n\}} k_{1, i}+\min _{i \in\{1, \ldots, n\}} k_{2, i}+1} \quad \text { and } \quad K=\frac{\left(1+\max _{i \in\{1, \ldots, n\}} k_{1, i}\right)}{\min _{i \in\{1, \ldots, n\}} k_{1, i}+\min _{i \in\{1, \ldots, n\}} k_{2, i}+1} .
$$

Then problem (1.1)-(1.2) has a unique solution $u$ in $E$. 
Proof We shall use Banach's fixed point theorem. For this we need to verify that $T$ is a contraction function. For all $i \in\{1, \ldots, n\}, u=\left(u_{1}, \ldots, u_{n}\right), v=\left(v_{1}, \ldots, v_{n}\right) \in E$, for each $t \in$ $[0,1]$, we have

$$
\begin{aligned}
\left|T_{i}(u)(t)-T_{i}(v)(t)\right| \leq & C \int_{0}^{1}\left|g_{i}(s, u(s))-g_{i}(s, v(s))\right| d s \\
& +K \int_{0}^{1}\left|h_{i}(s, u(s))-h_{i}(s, v(s))\right| d s \\
& +\int_{0}^{1} G_{1}(s)\left|f_{i}(s, u(s))-f_{i}(s, v(s))\right| d s \\
\leq & C \sum_{j=1}^{n} \int_{0}^{1} \varphi_{i, j}(s)\left|u_{j}(s)-v_{j}(s)\right| d s \\
& +K \sum_{j=1}^{n} \int_{0}^{1} \psi_{i, j}(s)\left|u_{j}(s)-v_{j}(s)\right| d s \\
& +\sum_{j=1}^{n} \int_{0}^{1} G_{1}(s) \theta_{i, j}(s)\left|u_{j}(s)-v_{j}(s)\right| d s \\
\leq & {\left[C \sum_{j=1}^{n} \int_{0}^{1} \varphi_{i, j}(s) d s+K \sum_{j=1}^{n} \int_{0}^{1} \psi_{i, j}(s) d s\right.} \\
& \left.+\sum_{j=1}^{n} \int_{0}^{1} G_{1}(s) \theta_{i, j}(s) d s\right]\|u-v\| .
\end{aligned}
$$

Then by the Cauchy-Schwarz inequality, for all $i \in\{1, \ldots, n\}$,

$$
\begin{aligned}
\left\|T_{i}(u)-T_{i}(v)\right\|_{\infty} \leq & {\left[C \sum_{j=1}^{n}\left\|\varphi_{i, j}\right\|_{L^{1}}+K \sum_{j=1}^{n}\left\|\psi_{i, j}\right\|_{L^{1}}+\sum_{j=1}^{n}\left\|G_{1}\right\|_{L^{2}}\left\|\theta_{i, j}\right\|_{L^{2}}\right] } \\
& \times\|u-v\|
\end{aligned}
$$

we deduce that

$$
\begin{aligned}
\|T(u)-T(v)\| \leq & \sum_{i=1}^{n}\left[C \sum_{j=1}^{n}\left\|\varphi_{i, j}\right\|_{L^{1}}+K \sum_{j=1}^{n}\left\|\psi_{i, j}\right\|_{L^{1}}+\sum_{j=1}^{n}\left\|G_{1}\right\|_{L^{2}}\left\|\theta_{i, j}\right\|_{L^{2}}\right] \\
& \times\|u-v\| .
\end{aligned}
$$

Since $C \sum_{i=1}^{n} \sum_{j=1}^{n}\left\|\psi_{i, j}\right\|_{L^{1}}+K \sum_{i=1}^{n} \sum_{j=1}^{n}\left\|\varphi_{i, j}\right\|_{L^{1}}+\sum_{i=1}^{n} \sum_{j=1}^{n}\left\|G_{1}\right\|_{L^{2}}\left\|\theta_{i, j}\right\|_{L^{2}}<1$, then $T$ is a contraction, hence it has a unique fixed point which is the unique solution of (1.1)-(1.2). The proof is completed.

We establish an existence result using the nonlinear alternative of Leray-Schauder type.

Lemma 3.3 (Leray-Schauder nonlinear alternative (see [29])) Let $F$ be a Banach space and $\Omega$ be a bounded open subset of $F, 0 \in \Omega$. Let $T: \bar{\Omega} \rightarrow F$ be a completely continuous operator. Then there exists $x \in \partial \Omega, \lambda>1$ such that $T(x)=\lambda x$, or there exists a fixed point $x^{*} \in \bar{\Omega}$. 
From this theorem we have the following result.

Theorem 3.4 Let $i \in\{1, \ldots, n\}$, assume that the functions $f_{i} \in C\left([0,1] \times \mathbb{R}^{n}, \mathbb{R}\right) g_{i} \in$ $C\left([0,1] \times \mathbb{R}^{n}, \mathbb{R}\right)$ and $h_{i} \in C\left([0,1] \times \mathbb{R}^{n}, \mathbb{R}\right)$ are continuous such that there exist continuous and nonnegative functions $\phi_{i}^{f}, \phi_{i}^{g}$, and $\phi_{i}^{h} \in L^{1}\left([0,1], \mathbb{R}_{+}\right), \psi_{i}^{f}, \psi_{i}^{g}$ and $\psi_{i}^{h} \in C\left(\mathbb{R}_{+}, \mathbb{R}_{+}\right)$ nondecreasing on $\mathbb{R}_{+}$and $r>0$ such that for all $\left(x_{1}, \ldots, x_{n}\right) \in \mathbb{R}^{n}$, for all $t \in[0,1]$

$$
\begin{aligned}
& \left|f_{i}\left(t, x_{1}, \ldots, x_{n}\right)\right| \leq \phi_{i}^{f}(t) \psi_{i}^{f}\left(\|x\|_{1}\right), \\
& \left|g_{i}\left(t, x_{1}, \ldots, x_{n}\right)\right| \leq \phi_{i}^{g}(t) \psi_{i}^{g}\left(\|x\|_{1}\right), \\
& \left|h_{i}\left(t, x_{1}, \ldots, x_{n}\right)\right| \leq \phi_{i}^{h}(t) \psi_{i}^{h}\left(\|x\|_{1}\right), \\
& \left\|G_{1}\right\|_{L^{2}} \sum_{i=1}^{n} \psi_{i}^{f}(r)\left\|\phi_{i}^{f}\right\|_{L^{2}}+C \sum_{i=1}^{n} \psi_{i}^{g}(r)\left\|\phi_{i}^{g}\right\|_{L^{1}}+K \sum_{i=1}^{n} \psi_{i}^{h}(r)\left\|\phi_{i}^{h}\right\|_{L^{1}}<r .
\end{aligned}
$$

Then the boundary value problem (1.1)-(1.2) has at least one nontrivial solution $u^{*} \in E$.

Proof First let us prove that $T$ is completely continuous.

(i) It is easy to see that for all $i \in\{1, \ldots, n\}, T_{i}$ are continuous since $f_{i}, g_{i}, h_{i}$, and $G_{i}$ are continuous. $T$ maps bounded sets into bounded sets in $E$; to establish this step, we use the Arzelà-Ascoli theorem [29]. Let $B_{\eta}=\{u \in E ;\|u\| \leq \eta\}$ be a bounded subset in $E$. We shall prove that $T\left(B_{\eta}\right)$ is relatively compact.

For $u \in B_{\eta}$ and using (3.3), (3.4), (3.5) and Lemma 3.1, we get for all $i \in\{1, \ldots, n\}$, for all $t \in[0,1]$,

$$
\begin{aligned}
\left|T_{i}(u)(t)\right| \leq & \int_{0}^{1} G_{1}(s) \phi_{i}^{f}(s) \psi_{i}^{f}\left(\|u(s)\|_{1}\right) d s+C \int_{0}^{1} \phi_{i}^{g}(s) \psi_{i}^{g}\left(\|u(s)\|_{1}\right) d s \\
& +K \int_{0}^{1} \phi_{i}^{h}(s) \psi_{i}^{h}\left(\|u(s)\|_{1}\right) d s .
\end{aligned}
$$

Since $\psi_{i}^{f}, \psi_{i}^{g}$, and $\psi_{i}^{h}$ are nondecreasing, then (3.7) becomes for all $i \in\{1, \ldots, n\}$, for all $t \in[0,1]$,

$$
\begin{aligned}
\left|T_{i}(u)(t)\right| \leq & \int_{0}^{1} G_{1}(s) \phi_{i}^{f}(s) \psi_{i}^{f}(\|u\|) d s+C \int_{0}^{1} \phi_{i}^{g}(s) \psi_{i}^{g}(\|u\|) d s \\
& +K \int_{0}^{1} \phi_{i}^{h}(s) \psi_{i}^{h}(\|u\|) d s \\
\leq & \psi_{i}^{f}(\eta) \int_{0}^{1} G_{1}(s) \phi_{i}^{f}(s) d s+C \psi_{i}^{g}(\eta) \int_{0}^{1} \phi_{i}^{g}(s) d s \\
& +K \psi_{i}^{h}(\eta) \int_{0}^{1} \phi_{i}^{h}(s) d s .
\end{aligned}
$$

Using the Cauchy-Schwarz inequality, we have for all $i \in\{1, \ldots, n\}$, for all $t \in[0,1]$,

$$
\left|T_{i}(u)(t)\right| \leq \psi_{i}^{f}(\eta)\left\|G_{1}\right\|_{L^{2}}\left\|\phi_{i}^{f}\right\|_{L^{2}}+C \psi_{i}^{g}(\eta)\left\|\phi_{i}^{g}\right\|_{L^{1}}+K \psi_{i}^{h}(\eta)\left\|\phi_{i}^{h}\right\|_{L^{1}} .
$$

Then, for all $i \in\{1, \ldots, n\}$,

$$
\left\|T_{i}(u)\right\|_{\infty} \leq \psi_{i}^{f}(\eta)\left\|G_{1}\right\|_{L^{2}}\left\|\phi_{i}^{f}\right\|_{L^{2}}+C \psi_{i}^{g}(\eta)\left\|\phi_{i}^{g}\right\|_{L^{1}}+K \psi_{i}^{h}(\eta)\left\|\phi_{i}^{h}\right\|_{L^{1}} .
$$


Consequently,

$$
\|T(u)\| \leq\left\|G_{1}\right\|_{L^{2}} \sum_{i=1}^{n} \psi_{i}^{f}(\eta)\left\|\phi_{i}^{f}\right\|_{L^{2}}+C \sum_{i=1}^{n} \psi_{i}^{g}(\eta)\left\|\phi_{i}^{g}\right\|_{L^{1}}+K \sum_{i=1}^{n} \psi_{i}^{h}(\eta)\left\|\phi_{i}^{h}\right\|_{L^{1}} .
$$

We deduce that $T$ maps bounded sets into bounded sets in $E$. It is easy to show that $T$ maps bounded sets into equicontinuous sets of $E$. By means of the Arzelà-Ascoli theorem [29], we deduce that $T$ is completely continuous.

(ii) Now, we apply the Leray-Schauder nonlinear alternative to prove that $T$ has at least a nontrivial solution in $E$. We define $\Omega=\{u \in E ;\|u\|<r\}$. Then, for $u \in \partial \Omega$ such that $u=\lambda T(u), 0<\lambda<1$, we have

$$
\begin{aligned}
\|u\|= & \lambda\|T(u)\| \leq\|T(u)\| \leq\left\|G_{1}\right\|_{L^{2}} \sum_{i=1}^{n} \psi_{i}^{f}(r)\left\|\phi_{i}^{f}\right\|_{L^{2}}+C \sum_{i=1}^{n} \psi_{i}^{g}(r)\left\|\phi_{i}^{g}\right\|_{L^{1}} \\
& +K \sum_{i=1}^{n} \psi_{i}^{h}(r)\left\|\phi_{i}^{h}\right\|_{L^{1}} .
\end{aligned}
$$

Using (3.6) we deduce that

$$
\|u\| \leq\left\|G_{1}\right\|_{L^{2}} \sum_{i=1}^{n} \psi_{i}^{f}(r)\left\|\phi_{i}^{f}\right\|_{L^{2}}+C \sum_{i=1}^{n} \psi_{i}^{g}(r)\left\|\phi_{i}^{g}\right\|_{L^{1}}+K \sum_{i=1}^{n} \psi_{i}^{h}(r)\left\|\phi_{i}^{h}\right\|_{L^{1}}<r,
$$

which is a contradiction to the fact that $u \in \partial \Omega$. Lemma 3.3 allows us to conclude that $T$ has a fixed point $u^{*} \in \bar{\Omega}$, and then problem (1.1)-(1.2) has a nontrivial solution $u^{*} \in E$. This achieves the proof.

\section{Existence of a positive solution}

In this section, we will give some preliminary considerations and some lemmas which are essential to establish sufficient conditions for the existence of at least one positive solution for our problem. We make the following additional assumption.

(H1) The functions $f_{i}:[0,1] \times \mathbb{R}_{+}^{n} \rightarrow \mathbb{R}_{+}, g_{i}:[0,1] \times \mathbb{R}_{+}^{n} \rightarrow \mathbb{R}_{+}$and $h_{i}:[0,1] \times \mathbb{R}_{+}^{n} \rightarrow \mathbb{R}_{+}$ are continuous.

(H2) For all $i \in\{1, \ldots, n\}$, there exist $\left.\left[\alpha_{i}, \beta_{i}\right] \subset\right] 0,1\left[\right.$ and $m_{1, i}>0$ such that $f_{i}(t, u) \geq m_{1, i}$ for all $t \in\left[\alpha_{i}, \beta_{i}\right], u \in \mathbb{R}_{+}^{n}$.

(H3) For all $i \in\{1, \ldots, n\}$, there exist $M_{1, i}>0, M_{2, i}>0$ and $M_{3, i}>0$ such that $f_{i}(t, u) \leq M_{1, i}, h_{i}(t, u) \leq M_{2, i}$ and $g_{i}(t, u) \leq M_{3, i}$ for all $u \in \mathbb{R}_{+}^{n}$.

Now, we need some properties of the Green functions $G_{i}(t, s)$ for $i \in\{1, \ldots, n\}$.

Lemma 4.1 Let $a \in] 0,1[, b \in] 0,1[$, then for all $(t, s) \in[a, b] \times[a, b]$, for all $i \in\{1, \ldots, n\}$, we have

$$
G_{i}(t, s) \geq L(a, b),
$$

where

$$
L(a, b)=\frac{\left(a+\min _{i \in\{1, \ldots, n\}} k_{1, i}\right)\left(1-b+\min _{i \in\{1, \ldots, n\}} k_{2, i}\right)}{\max _{i \in\{1, \ldots, n\}} k_{1, i}+\max _{i \in\{1, \ldots, n\}} k_{2, i}+1} .
$$


The proof of Lemma 4.1 is similar to that of Lemma 3.1.

Definition 4.2 Let $E$ be a Banach space. A nonempty closed convex $C \subset E$ is called a cone if it satisfies the following two conditions:

1. $x \in C, \lambda \geq 0$ implies $\lambda x \in C$;

2. $x \in C,-x \in C$ implies $x=0$.

\section{Remark 4.3}

$$
\mathbf{C}=\left\{u=\left(u_{1}, \ldots, u_{n}\right) \in E, u_{i}(t) \geq 0, t \in[0,1], i \in\{1, \ldots, n\}\right\}
$$

is a cone of $E$.

Theorem 4.4 (Guo-Krasnoselskii's fixed point theorem in cone [30]) Let E be a Banach space, and let $K \subset E$ be a cone. Assume that $\Omega_{1}$ and $\Omega_{2}$ are two bounded open subsets of $E$ with $0 \in \Omega_{1}$ and $\bar{\Omega}_{1} \subset \Omega_{2}$. Let $A: K \cap\left(\bar{\Omega}_{2} \backslash \Omega_{1}\right) \rightarrow K$ be a completely continuous operator such that:

1. $\|A(u)\| \leq\|u\|, u \in K \cap \partial \Omega_{1}$ and $\|A(u)\| \geq\|u\|, u \in K \cap \partial \Omega_{2}$ or

2. $\|A(u)\| \geq\|u\|, u \in K \cap \partial \Omega_{1}$ and $\|A(u)\| \leq\|u\|, u \in K \cap \partial \Omega_{2}$.

Then $A$ has a fixed point in $K \cap\left(\bar{\Omega}_{2} \backslash \Omega_{1}\right)$.

We employ Guo-Krasnoselskii's fixed point theorem in cone to prove the existence of a positive solution of our problem, we have the following theorem.

Theorem 4.5 Assume that conditions (H1), (H2) and (H3) hold. Then equation (1.1)-(1.2) has at least one positive solution.

Proof Remark 4.3 shows that $\mathbf{C}$ is a cone subset of $E$. Lemma 3.1 and (H1) show that $T$ : $\mathbf{C} \rightarrow \mathbf{C}$. In addition, a standard argument involving the Arzelà-Ascoli theorem implies that $T$ is a completely continuous operator.

Let $i \in\{1, \ldots, n\}$. From (H1) and (H2) there exist $\left.\left[\alpha_{i}, \beta_{i}\right] \subset\right] 0,1\left[\right.$ such that for all $s \in\left[\alpha_{i}, \beta_{i}\right]$, $f_{i}(s, u) \geq m_{1, i}$ for all $u \in \mathbb{R}_{+}^{n}$. Then, for all $t \in[0,1], T_{i}(u)(t) \geq\left(\beta_{i}-\alpha_{i}\right) m_{1, i} L\left(\alpha_{i}, \beta_{i}\right)$. Now, we choose a positive constant $R_{1}$ such that $R_{1} \leq \sum_{i=1}^{n}\left(\beta_{i}-\alpha_{i}\right) m_{1, i} L\left(\alpha_{i}, \beta_{i}\right)$ and define $\Omega_{1}=$ $\left\{u \in E:\|u\|<R_{1}\right\}$. For any $u \in \mathbf{C} \cap \partial \Omega_{1}$, from the condition $\left\|T_{i}(u)\right\|_{\infty} \geq T_{i}(u)(t) \geq\left(\beta_{i}-\right.$ $\left.\alpha_{i}\right) m_{1, i} L\left(\alpha_{i}, \beta_{i}\right)$ we get $\|T(u)\| \geq \sum_{i=1}^{n}\left(\beta_{i}-\alpha_{i}\right) m_{1, i} L\left(\alpha_{i}, \beta_{i}\right) \geq R_{1}=\|u\|$. Thus, for any $u \in$ $\mathbf{C} \cap \partial \Omega_{1}$, we find that

$$
\|T(u)\| \geq\|u\|
$$

Let $R_{2}=\max \left\{\sum_{i=1}^{n} M_{1, i} \int_{0}^{1} G_{1}(s) d s+K M_{2, i}+C M_{3, i}, 2 R_{1}\right\}$ and we define $\Omega_{2}=\{u \in E:\|u\|<$ $\left.R_{2}\right\}$. Clearly, $\bar{\Omega}_{1} \subset \Omega_{2}$ and for any $u \in \mathbf{C} \cap \partial \Omega_{2}$, we obtain $\left\|T_{i}(u)\right\|_{\infty} \leq M_{1, i} \int_{0}^{1} G_{1}(s) d s+$ $K M_{2, i}+C M_{3, i}$, then $\|T(u)\| \leq \sum_{i=1}^{n} M_{1, i} \int_{0}^{1} G_{1}(s) d s+K M_{2, i}+C M_{3, i} \leq R_{2}=\|u\|$. Thus, for any $u \in \mathbf{C} \cap \partial \Omega_{2}$, it implies that

$$
\|T(u)\| \leq\|u\| .
$$


Based on Theorem 4.4, we get from (4.1) and (4.2) that the operator $T$ has at least one fixed point. Thus, it follows that (1.1)-(1.2) has at least one nonnegative solution and from (H1) and (H2), (1.1)-(1.2) has at least one positive solution.

Finally, we give some examples to illustrate the results obtained in this paper.

Example 4.6 Consider the following system of boundary value problem:

$$
\left\{\begin{array}{l}
u_{i}^{\prime \prime}(t)+f_{i}\left(t, u_{1}(t), u_{2}(t), u_{3}(t)\right)=0, \quad 0<t<1, i \in\{1,2,3\} \\
u_{i}(0)-k_{1, i} u_{i}^{\prime}(0)=\int_{0}^{1} g_{i}\left(s, u_{1}(s), u_{2}(s), u_{3}(s)\right) d s \\
u_{i}(1)+k_{2, i} u_{i}^{\prime}(1)=\int_{0}^{1} h_{i}\left(s, u_{1}(s), u_{2}(s), u_{3}(s)\right) d s
\end{array}\right.
$$

with

$$
\begin{aligned}
& f_{i}\left(t, x_{1}, x_{2}, x_{3}\right)=\frac{(t+i)^{4}}{240} x_{1}+\frac{(t+i+1)^{3}}{240} x_{2}+\frac{1}{120 i} \cos \left(x_{3}\right), \\
& g_{i}\left(t, x_{1}, x_{2}, x_{3}\right)=\frac{t^{i}}{240} x_{1}+\frac{(t+1)^{3 i}}{240} x_{2}+\frac{1}{240} \cos \left(x_{3}\right), \\
& h_{i}\left(t, x_{1}, x_{2}, x_{3}\right)=\frac{(\sqrt{t+1})^{i}}{240} x_{1}+\frac{(t+1)^{3}}{240} x_{2}+\frac{1}{960} x_{3},
\end{aligned}
$$

$k_{1,1}=\frac{1}{6,265}, k_{1,2}=\frac{1}{8,887}, k_{1,3}=\frac{1}{1,252}, k_{2,1}=\frac{1}{2,185}, k_{2,2}=\frac{1}{2,300}$ and $k_{2,3}=\frac{1}{2,415}$. We have

$$
\begin{aligned}
& \left|f_{i}\left(t, x_{1}, x_{2}, x_{3}\right)-f_{i}\left(t, y_{1}, y_{2}, y_{3}\right)\right| \leq \theta_{i, 1}(t)\left|x_{1}-y_{1}\right|+\theta_{i, 2}(t)\left|x_{2}-y_{2}\right|+\theta_{i, 3}(t)\left|x_{3}-y_{3}\right|, \\
& \left|g_{i}\left(t, x_{1}, x_{2}, x_{3}\right)-f_{i}\left(t, y_{1}, y_{2}, y_{3}\right)\right| \leq \varphi_{i, 1}(t)\left|x_{1}-y_{1}\right|+\varphi_{i, 2}(t)\left|x_{2}-y_{2}\right|+\varphi_{i, 3}(t)\left|x_{3}-y_{3}\right|, \\
& \left|h_{i}\left(t, x_{1}, x_{2}, x_{3}\right)-f_{i}\left(t, y_{1}, y_{2}, y_{3}\right)\right| \leq \psi_{i, 1}(t)\left|x_{1}-y_{1}\right|+\psi_{i, 2}(t)\left|x_{2}-y_{2}\right|+\psi_{i, 3}(t)\left|x_{3}-y_{3}\right|,
\end{aligned}
$$

where $\theta_{i, 1}(t)=\frac{(t+i)^{4}}{240}, \theta_{i, 2}(t)=\frac{(t+i+1)^{3}}{240}, \theta_{i, 3}(t)=\frac{1}{120 i}, \varphi_{i, 1}(t)=\frac{t^{i}}{240}, \varphi_{i, 2}(t)=\frac{(t+1)^{3 i}}{240}, \varphi_{i, 3}(t)=\frac{1}{240}$, $\psi_{i, 1}(t)=\frac{(\sqrt{t+1})^{i}}{240}, \psi_{i, 2}(t)=\frac{(t+1)^{3}}{240}, \psi_{i, 3}(t)=\frac{1}{960}, C=1.99963$ and $K=0.999586$.

$$
C \sum_{i=1}^{3} \sum_{j=1}^{3}\left\|\psi_{i, j}\right\|_{L^{1}}+K \sum_{i=1}^{3} \sum_{j=1}^{3}\left\|\varphi_{i, j}\right\|_{L^{1}}+\sum_{i=1}^{3} \sum_{j=1}^{3}\left\|G_{1}\right\|_{L^{2}}\left\|\theta_{i, j}\right\|_{L^{2}}=0.959871<1 .
$$

Then from Theorem 3.2 we conclude that the system of boundary value problem has a unique solution $u^{*} \in E$.

Example 4.7 Consider the following system of boundary value problem:

$$
\left\{\begin{array}{l}
u_{i}^{\prime \prime}(t)+f_{i}\left(t, u_{1}(t), u_{2}(t), u_{3}(t)\right)=0, \quad 0<t<1, i \in\{1,2,3\} \\
u_{i}(0)-k_{1, i} u_{i}^{\prime}(0)=\int_{0}^{1} g_{i}\left(s, u_{1}(s), u_{2}(s), u_{3}(s)\right) d s \\
u_{i}(1)+k_{2, i} u_{i}^{\prime}(1)=\int_{0}^{1} h_{i}\left(s, u_{1}(s), u_{2}(s), u_{3}(s)\right) d s
\end{array}\right.
$$

with

$$
f_{i}\left(t, x_{1}, x_{2}, x_{3}\right)=\left(\frac{1}{2+2 t^{2}}\right) \frac{1}{i+e^{i\left(\left|x_{1}\right|+\left|x_{2}\right|+\left|x_{3}\right|\right)}},
$$




$$
\begin{aligned}
& g_{i}\left(t, x_{1}, x_{2}, x_{3}\right)=\left(\frac{1}{2+2 e^{i t}}\right) \frac{1}{\left(1+e^{i\left(\left|x_{1}\right|+\left|x_{2}\right|+\left|x_{3}\right|\right)}\right)^{4}}, \\
& h_{i}\left(t, x_{1}, x_{2}, x_{3}\right)=\left(\frac{1}{1+2 t}\right) \frac{1}{1+i\left(\left|x_{1}\right|+\left|x_{2}\right|+\left|x_{3}\right|\right)},
\end{aligned}
$$

$k_{1,1}=\frac{1}{132,651}, k_{1,2}=\frac{1}{140,608}, k_{1,3}=\frac{1}{148,877}, k_{2,1}=\frac{1}{19}, k_{2,2}=\frac{1}{20}, k_{2,3}=\frac{1}{21}, C=1.95932$ and $K=$ 0.954547. In this case we have

$$
\left|f_{i}\left(t, x_{1}, x_{2}, x_{3}\right)\right| \leq \phi_{i}^{f}(t) \psi_{i}^{f}\left(\left|x_{1}\right|+\left|x_{2}\right|+\left|x_{3}\right|\right),
$$

where

$$
\begin{aligned}
& \phi_{i}^{f}(t)=\frac{1}{1+t^{2}}, \quad \psi_{i}^{f}(r)=\frac{1}{i+e^{i r}}, \\
& \left|g_{i}\left(t, x_{1}, x_{2}, x_{3}\right)\right| \leq \phi_{i}^{g}(t) \psi_{i}^{g}\left(\left|x_{1}\right|+\left|x_{2}\right|+\left|x_{3}\right|\right),
\end{aligned}
$$

where

$$
\begin{aligned}
& \phi_{i}^{g}(t)=\frac{1}{1+e^{i t}}, \quad \psi_{i}^{g}(r)=\frac{1}{\left(1+e^{i r}\right)^{4}}, \\
& \left|h_{i}\left(t, x_{1}, x_{2}, x_{3}\right)\right| \leq \phi_{i}^{h}(t) \psi_{i}^{h}\left(\left|x_{1}\right|+\left|x_{2}\right|+\left|x_{3}\right|\right),
\end{aligned}
$$

where

$$
\phi_{i}^{h}(t)=\frac{1}{1+t}, \quad \psi_{i}^{h}(r)=\frac{1}{1+i r} .
$$

For $r=4$, we find

$$
\left\|G_{1}\right\|_{L^{2}} \sum_{i=1}^{3} \psi_{i}^{f}(r)\left\|\phi_{i}^{f}\right\|_{L^{2}}+C \sum_{i=1}^{3} \psi_{i}^{g}(r)\left\|\phi_{i}^{g}\right\|_{L^{1}}+K \sum_{i=1}^{3} \psi_{i}^{h}(r)\left\|\phi_{i}^{h}\right\|_{L^{1}}=0.838<4
$$

Then from Theorem 3.4 we conclude that the system of boundary value problem has at least one solution $u^{*} \in E$.

Example 4.8 Consider the following system of boundary value problem:

$$
\left\{\begin{array}{l}
u_{1}^{\prime \prime}(t)+2+\frac{1}{2 \sqrt{1+t^{4}}} e^{-\left(\left(u_{1}(t)\right)^{2}+\left(u_{2}(t)\right)^{2}\right)+\sqrt{t+6}}=0, \quad 0<t<1, \\
u_{2}^{\prime \prime}(t)+5+\frac{1}{2 \sqrt{1+t^{4}}} e^{-\left(\left(u_{1}(t)\right)^{2}+\left(u_{2}(t)\right)^{2}\right)}=0, \quad 0<t<1, \\
u_{1}(0)-k_{1,1} u_{1}^{\prime}(0)=\int_{0}^{1} \frac{\sin \left(s\left(\left|u_{1}(s)\right|+\left|u_{2}(s)\right|\right)\right)}{\left(\left|u_{1}(s)\right|+\left|u_{2}(s)\right|\right)^{2}+1} d s \\
u_{1}(1)+k_{2,1} u_{1}^{\prime}(1)=\int_{0}^{1} \frac{s\left(\left|u_{1}(s)\right|+\left|u_{2}(s)\right|\right) e^{-s\left(\left|u_{1}(s)\right|+\left|u_{2}(s)\right|\right)}}{\sqrt{\left(\left|u_{1}(s)\right|+\left|u_{2}(s)\right|\right)^{2}+1}} d s \\
u_{2}(0)-k_{1,2} u_{2}^{\prime}(0)=\int_{0}^{1} \frac{\cos \left(s\left(\left|u_{1}(s)\right|+\left|u_{2}(s)\right|\right) \mid\right.}{\left(\left|u_{1}(s)\right|+\left|u_{2}(s)\right|\right)^{2}+1} d s \\
u_{2}(1)+k_{2,2} u_{2}^{\prime}(1)=\int_{0}^{1} \frac{e^{-s\left(\left|u_{1}(s)\right|+\left|u_{2}(s)\right|\right)}}{\left(\left|u_{1}(s)\right|+\left|u_{2}(s)\right|\right)^{2}+1} d s
\end{array}\right.
$$

where $k_{i, j} \geq 0$ for all $i, j \in\{1,2\}$. Let

$$
f_{1}\left(t, x_{1}, x_{2}\right)=2+\frac{1}{2 \sqrt{1+t^{4}}} e^{-\left(x_{1}^{2}+x_{2}^{2}\right)+\sqrt{t+6}}
$$




$$
\begin{aligned}
& f_{2}\left(t, x_{1}, x_{2}\right)=5+\frac{1}{2 \sqrt{1+t^{4}}} e^{-\left(x_{1}^{2}+x_{2}^{2}\right)}, \\
& g_{1}\left(t, x_{1}, x_{2}\right)=\frac{\sin \left(t\left(\left|x_{1}\right|+\left|x_{2}\right|\right)\right)}{\left(\left|x_{1}\right|+\left|x_{2}\right|\right)^{2}+1} \\
& h_{1}\left(t, x_{1}, x_{2}\right)=\frac{t\left(\left|x_{1}\right|+\left|x_{2}\right|\right) e^{-t\left(\left|x_{1}\right|+\left|x_{2}\right|\right)}}{\sqrt{\left(\left|x_{1}\right|+\left|x_{2}\right|\right)^{2}+1}}, \\
& g_{2}\left(t, x_{1}, x_{2}\right)=\frac{\cos \left(t\left(\left|x_{1}\right|+\left|x_{2}\right|\right)\right)}{\left(\left|x_{1}\right|+\left|x_{2}\right|\right)^{2}+1}
\end{aligned}
$$

and

$$
h_{2}\left(t, x_{1}, x_{2}\right)=\frac{e^{-t\left(\left|x_{1}\right|+\left|x_{2}\right|\right)}}{\left(\left|x_{1}\right|+\left|x_{2}\right|\right)^{2}+1}
$$

We can easily show that conditions (H1), (H2) and (H3) are satisfied. Hence, by Theorem 4.5 this problem has at least one positive solution.

\section{Competing interests}

The authors declare that they have no competing interests.

\section{Authors' contributions}

All authors contributed equally to the writing of this paper. All authors read and approved the final manuscript.

\section{Acknowledgements}

The authors thank the reviewers for their constructive remarks that led to the improvement of the original manuscript.

Received: 24 July 2014 Accepted: 11 November 2014 Published online: 16 December 2014

\section{References}

1. Bebernes, J, Eberly, D: Mathematical Problems from Combustion Theory. Applied Math. Sci., vol. 83. Springer, New York (1989)

2. Joseph, DD, Sparrow, EM: Nonlinear diffusion induced by nonlinear sources. Q. Appl. Math. 28, 327-342 (1970)

3. Keller, HB, Cohen, DS: Some positone problems suggested by nonlinear heat generation. J. Math. Mech. 16, 1361-1376 (1967)

4. Guezane-Lakoud, A, Belakroum, D: Rothe's method for telegraph equation with integral conditions. Nonlinear Anal. 70, 3842-3853 (2009)

5. Yang, ZL, Sun, JX: Positive solutions of boundary value problems for systems of nonlinear second order ordinary differential equations. Acta Math. Sin. 47, 111-118 (2004)

6. Ma, R: Existence of positive radial solutions for elliptic systems. J. Math. Anal. Appl. 201, 375-386 (1996)

7. Khan, RA: The generalized method of quasilinearization and nonlinear boundary value problems with integral boundary conditions. Electron. J. Qual. Theory Differ. Equ. 2003, 19 (2003)

8. Ahmed, B, Alsaed, A, Alghamdi, BS: Analytic approximation of solutions of the forced Duffing equation with integral boundary conditions. Nonlinear Anal., Real World Appl. 9, 1727-1740 (2008)

9. Benchohra, M, Nieto, JJ, Ouahab, A: Second-order boundary value problem with integral boundary conditions. Bound. Value Probl. 2011, Article ID 260309 (2011)

10. Belarbi, A, Benchohra, M, Ouahab, A: Multiple positive solutions for nonlinear boundary value problems with integral boundary conditions. Arch. Math. 44, 1-7 (2008)

11. Liu, B: Positive solutions of fourth-order two point boundary value problems. Appl. Math. Comput. 148, 407-420 (2004)

12. Sun, Y, Liu, L: Solvability for a nonlinear second-order three-point boundary value problem. J. Math. Anal. Appl. 296, 265-275 (2004)

13. Yang, B: Positive solutions for a fourth order boundary value problem. Electron. J. Qual. Theory Differ. Equ. 2005, 3 (2005)

14. Agarwal, RP, O'Regan, D, Lakshmikantham, V, Leela, S: An upper and lower solution theory for singular Emden-Fowler equations. Nonlinear Anal., Real World Appl. 3, 275-291 (2002)

15. Il'in, VA, Moiseev, El: Nonlocal boundary value problem of the second kind for the Sturm-Liouville operator. J. Differ. Equ. 23, 979-987 (1987)

16. Webb, JRL, Infante, G: Positive solutions of nonlocal boundary value problems: a unified approach. J. Lond. Math. Soc. 74, 673-693 (2006)

17. Sun, Y, Liu, L, Zhang, J, Agarwal, RP: Positive solutions of singular three-point boundary value problems for second-order differential equations. J. Comput. Appl. Math. 230, 738-750 (2009) 
18. Agarwal, RP, O'Regan, D, Lakshmikantham, V, Leela, S: Existence of positive solutions for singular initial and boundary value problems via the classical upper and lower solution approach. Nonlinear Anal. 50, 215-222 (2002)

19. Wong, PJY: A system of $\left(n_{i}, p_{i}\right)$ boundary value problems with positive/nonpositive nonlinearities. J. Math. Anal. Appl. 243, 293-312 (2000)

20. Agarwal, RP, O'Regan, D, Lakshmikantham, V: Nonuniform nonresonance at the first eigenvalue for singular boundary value problems with sign changing nonlinearities. J. Math. Anal. Appl. 274, 404-423 (2002)

21. Rachunkovà, I: Boundary value problems with nonlinear conditions. Acta Math. Inform. Univ. Ostrav. 2, 71-77 (1994)

22. Rachunkovà, I: Sign conditions in nonlinear boundary value problems. Acta Univ. Palacki. Olomuc., Fac. Rerum Nat., Math. 33, 117-124 (1994)

23. Infante, G, Pietramala, P, Tenuta, M: Existence and localization of positive solutions for a nonlocal BVP arising in chemical reactor theory. Commun. Nonlinear Sci. Numer. Simul. 19, 2245-2251 (2014)

24. Goodrich, CS: Nonlocal systems of BVPs with asymptotically superlinear boundary conditions. Comment. Math. Univ. Carol. 53, 79-97 (2012)

25. Goodrich, CS: Nonlocal systems of BVPs with asymptotically sublinear boundary conditions. Appl. Anal. Discrete Math. 6, 174-193 (2012)

26. Infante, G, Pietramala, P: Existence and multiplicity of non-negative solutions for systems of perturbed Hammerstein integral equations. Nonlinear Anal. 71, 1301-1310 (2009)

27. Infante, G, Minhós, FM, Pietramala, P: Non-negative solutions of systems of ODEs with coupled boundary conditions. Commun. Nonlinear Sci. Numer. Simul. 17, 4952-4960 (2012)

28. Infante, G, Pietramala, P: Multiple nonnegative solutions of systems with coupled nonlinear boundary conditions. Math. Methods Appl. Sci. 37, 2080-2090 (2014)

29. Deimling, K: Nonlinear Functional Analysis. Springer, Berlin (1985)

30. Guo, D, Lakshmikantham, V: Nonlinear Problems in Abstract Cones. Academic Press, San Diego (1988)

doi:10.1186/s13661-014-0262-8

Cite this article as: Jebari and Boukricha: Solvability and positive solution of a system of second-order boundary value problem with integral boundary conditions. Boundary Value Problems 2014 2014:262.

\section{Submit your manuscript to a SpringerOpen ${ }^{\circ}$ journal and benefit from:}

- Convenient online submission

- Rigorous peer review

- Immediate publication on acceptance

- Open access: articles freely available online

- High visibility within the field

- Retaining the copyright to your article 